\title{
The effectiveness on sociality and social relationship by therapeutic recreation based on partner and group activity in the institutionalized elderly
}

\author{
Hyunna Kim* \\ Department of Social Welfare, Cheongam College, Suncheon, Korea
}

This research examined the effects on sociality and social relationship of therapeutic recreation program (TRP) based on partner and group activity in the institutionalized elderly as the level of psycho-social rehabilitations. TRP sessions were designed to encourage interaction and social relationship between two people or groups performing different types of tasks applied on Mosey's 5-step interaction skills. TRP was conducted for a total of 8 sessions, once a week, for 8 weeks. Using a pre-post experimental design, eight volunteer's data were analyzed to examine changes in sociality and social relationship. As the result, the degree of sociality was significantly changed from 3.14 to $3.73(P=$
0.002), as well as notable improvements of social relationships were found to have statistically increased from 3.27 to $4.10(P=0.001)$. Therefore, this study suggests that partner and group-based recreation programs while considering how and when facilitate interaction between participants should be applied as a way to solve the social problems and isolation of the elderly in the future.

Keywords: Sociality, Social relationship, Therapeutic recreation, Partner and group activity, Institutionalized elderly

\section{INTRODUCTION}

Aging makes not only physical decline but also social losses such as isolation, a sense of alienation, low income and dependence. Social isolation represents one of the most serious social problems of our time, ironically in an age when connection with others seems easy (Glover, 2017). It will impact health, well-being and quality of life of numerous older adults now and foreseeable future (Nicholson, 2012). Social isolation has been associated with symptoms of depression and diagnosis of congestive heart failure. Prevention and alleviating social isolation and loneliness among older people is an important area for leisure studies, however, preliminary literature also suggests to lack reports of effective interventions to mitigate social isolation (Cattan and White, 1998; Cattan et al., 2005; Findlay, 2003).

The reason of isolation is not only environment but also lack of sense of belongings and engagement with others. If social isola-

tion is detected early, future morbidity and mortality could be avoided through prevention and mitigation efforts (Nicholson, 2012). Social isolation can be reduced by living with a partner/ spouse, maintaining physical health, and participating social activities (Yang, 2018) and it has been confirmed that there is an inhibitory effect of decreasing suicidal thoughts (Lee, 2012). Kim (2000) emphasized social wellness as the ability to build healthy, nurturing and supportive relationships, and to foster a strong connection with others. Educational and social activity group interventions that target specific groups can alleviate social isolation and loneliness among older people (Cattan et al., 2005).

Therapeutic recreation (TR) can be defined leisure based professional interventions reflecting individual needs and interests using diverse facilitation techniques. Buettner and Voelkl (2006) demonstrate the efficacy of TR services supporting the functional independence, health and quality of life of older adults. In their systematic review of published articles, they revealed that being

${ }^{*}$ Corresponding author: Hyunna Kim (iD https://orcid.org/0000-0002-7684-554X Department of Social welfare, Cheongam College, 1641 Noksek-ro, Suncheon 57997, Korea

Tel: +82-61-740-7255, Fax: +82-61-740-7298, E-mail: hyunna73@naver.com Received: April 14, 2018 / Accepted: May 30, 2018
This is an Open Access article distributed under the terms of the Creative Commons Attribution Non-Commercial License (http://creativecommons.org/licenses/by-nc/4.0/) which permits unrestricted non-commercial use, distribution, and reproduction in any medium, provided the original work is properly cited. 
active and engaged in recreation can prevent and help treat many of the most common chronic medical conditions associated with older age. Linking a social component to any intervention addresses the area of loneliness and isolation so common in older people who have lost a spouse. Additionally, community-based pedometer programs and nursing home TR sessions are major contributors to the lives of older adults.

Data from the Normative Aging Study were used to examine whether specific groups of leisure activities moderated the effect of stress on the health of elderly men after divided 2 groups, bereaved and nonbereaved. As the results, mixed leisure activities of both group of men moderated the effect of stress on physical health. Even nonbereaved group, social activities moderated the effects of stress on physical health (Fitzpatrick et al., 2001).

Poscia et al. (2018) systemically reviewed the existing intervention for alleviating loneliness and social isolation among older persons. They suggested new technology and community engaged arts as a promising tool for tackling social isolation and loneliness.

Kahlbaugh et al. (2011) investigated physical activity loneliness and moods of the elderly while either playing Wii or watching television with a partner. The elderly playing Wii had lower loneliness and a pattern of greater positive mood compared to the television group. From this research, we predict doing any activity such as Wii with partner, particularly affect positive social connection and enjoyment.

According to these studies, it can be found to overcome social isolation or loneliness by participating in active social activities or leisure activities, or especially with others, based on the community. However, Participation in social activities is limited if there is a lack of sociality or if the social relationship with peers is not good. Lack of sociality or low social relationship can occur due to few social contacts with others or poor relationship quality. Furthermore, elderly people living in facility have low self-esteem, social support intervention and intervention through exercise may help to increase self-esteem for the elderly (Chung, 2004).

Therefore, this research was designed and applied the program for facilitating mutual exchange and interpersonal contact thereby breaking social isolation in the institutionalized elderly. Also, changes in sociality and social relationship were seen as the main variables that could observe the social isolation of the elderly. In particular, this study applied Mosey's 5 level of group interaction skills to develop sociality and social relationship.

Mosey's group interaction skills has been applied to develop group relationships of children, adolescents and adults by examining the issue of group interaction skills, group activities and group therapeutic intervention of occupational therapy treatment (Mosey, 1970). Mosey (1970) described 5 levels of group interaction skills: parallel, project, egocentric cooperative, cooperative and mature. Individuals in the group try to know each other with some verbal and nonverbal interactions at first. Then they do more joint interaction while implementing short-term and longterm tasks by stages. Cooperative task in third stage makes them to show more feeling and self-experience, interaction with group and environment develop a mature relationship that they can control balance between personal needs and group satisfaction while completing group task. Interaction between members develops and progresses gradually through the levels by members completing tasks when emphasize ever increasing cooperation and communication.

TRP of this research plan to make partner and group partner and group activity following Mosey's 5 step group interaction skill stage for giving proper personal contact and tasks. In the first phase, introductory activity to know each other and minimal interaction was planned, then giving familiar task for promoting enjoyment and help each other as a project group level. After that, select longer and more complex tasks such as cooking, playing different musical instruments and arts and crafts to foster group problemsolving. At the last stage, craft fair was held for encouraging feeling, self-expression, being comfortable and taking flexible roles within groups, even was not enough time to develop into a mature group level. From 3 sessions, manito by two persons was chosen and has set up a rule to help and doing good thing with each other even in everyday lives for encouraging mutual interaction.

\section{MATERIALS AND METHODS}

\section{Participants}

This study used a classical pre-post experimental design. Fourteen participants received prescribed TR once a week for 8 weeks as a group for improving sociality of the elderly. Participants were recruited person who were 65 years of age or older, can communicate with others and agree to the program in a residential facility, in Suncheon city, Korea. Eight of the 14 participants who started the study, only eight completed all sessions. Therefore, only their surveys were used for analysis. The final participants in this study consisted of $38 \%$ males $(n=3)$ and $63 \%$ females $(n=5)$ with a mean age of 77 years old.

\section{TR sessions}

TR sessions used recreation activity appropriate to the social in- 
Table 1. Therapeutic recreation sessions

\begin{tabular}{llll}
\hline Session & \multicolumn{1}{c}{ Mosey's group level } & \multicolumn{1}{c}{ Activity } \\
\hline 1 & Parallel group level & Welcome ceremony: program oath & Tell and promise to participate program \\
2 & & Name card making & Pick the partners image in the book and introduce each other \\
3 & Project group level & Partner game & Choose manito and do the game together \\
4 & & Folk activity & Play 'Yut' and Korean folk games and tell their memory \\
5 & Eco centric cooperative group level & Cooking and gift making & Decorate the cup cake and present and one of cake to their friend \\
6 & & Team music & Sing a song and play musical instrument with team \\
7 & & Eco bag making & Make eco bag and praise friend's work of art \\
8 & Cooperative and mature group level & Craft fair & Exhibit literary works and pictures, share feeling about program and Manito \\
\hline
\end{tabular}

teraction (partner name card making, partner game, Korean folk activity, cooking and gift giving, team music, couple eco bag making) by applying Mosey's 5-step interaction skill as show in the Table 1. During the sessions, participants can have several opportunities to help each other or share something in order to facilitate sociality and social relationships. The program was conducted by one TR specialist and five assistants, each session consisted of approximately 50 min taking into account the participant's age and abilities.

\section{Measurement}

Sociality was measured using the 22-item sociality evaluation scale used in Shin and Lim (2010). It is consisted of six subfactors, scalability, intimacy, reliability, cohesion, competence, and integrity with items scored from 0 to 5 ; higher scores indicate greater sociality. This scale has good internal consistency, reliability, and validity.

Social relationship was measured using the 27-item Relationship Change Scale (RCS). RCS consisted of six subfactors, satisfaction, communication, confidence, friendliness, sensibility, openness, understanding. It has been used many articles for measuring change of relationship after certain interventions (Choi et al., 2008; Samarel et al., 1997).

\section{Data analysis}

Data were collected using convenience sampling from the institutionalized organization. Sociality and social relationship were measured before and after intervention. This study analyzed eight persons data who participated whole sessions. Data analyses were driven by SPSS ver. 11 (SPSS Inc., Chicago, IL, USA). Statistical analyses were performed using $t$-test and one way analysis of variance.
Table 2. The changes of sociality and social relationship after intervention

\begin{tabular}{lcccc}
\hline Variable & Pre & Post & $t$ & $P$-value \\
\hline Sociality & $3.14 \pm 0.40071$ & $3.73 \pm 0.30516$ & -4.719 & 0.002 \\
Social relationship & $3.27 \pm 0.49281$ & $4.10 \pm 0.42678$ & -5.353 & 0.001 \\
\hline
\end{tabular}

Values are presented as mean \pm standard deviation.

\section{RESULTS}

The partner and group based TR program showed significant improvements on sociality and social relationship. Table 2 shows the changes in sociality and social relationship after 7 weeks of TPR intervention. Sociality was significantly improved from 3.14 to $3.73(P=0.002)$. Social relationship was found statistically improved from 3.27 before to 4.10 after $(P=0.001)$.

\section{DISCUSSION}

This study got attention social isolation very related to feeling of loneliness, symptoms of depression, the quality of life and even death rate in old age. Although the social isolation of the elderly is emerging as a very serious social issue, there are not enough effective and evident interventions to solve it (Cattan et al., 2005; Glover, 2017).

Cattan et al. (2005) found group interventions involving some form of educational or training input, and social activities that targeted specific group of people provide clear evidence to alleviate and prevent social isolation and loneliness among older people. Cohen-Mansfield (2018) applied 10 different types of group activities for improving quality of life of persons with dementia, significant relationships between the type of activity and ratings of engagement and mood were also found. Social cognitive training, support groups, social skills training, and reminiscence groups have been worked to reduce social isolation in older adults (Fokkema and Knipscheer, 2007; Hill et al., 2006; Stewart et al., 
2001).

All these studies used group-based intervention and positively changed the loneness and psycho-social aspects. This study also planned to work with partner of groups, so significant results on sociality and social support of the elderly. It shows that group-centered intervention using incorporating, social activities known for isolation and personal control is essential to improve the longterm effectiveness.

Some studies have validated the effectiveness of certain, specific activity. Tsai et al. (2010) evaluated a video conference program which aimed to facilitate contact between an older person and their family. They reported lower levels of loneliness among those using the videoconference. Horticultural activities helped to increase patients' self-confidence and self-expression, to improve their social skills, and to promote positive thinking (Getz et al., 1982). Cohen-Mansfield and Perach (2015) emphasized the value of specific therapy technique for reducing loneliness among older persons. In these researches, there was a process of giving and taking emotion or assignments. Great level of social support at the onset of the interventions was more likely to maintain reduced loneliness (McAuley and Blissmer, 2000). Burton et al. (2018) verified that peers involvement and support were effective in promoting and maintaining adherence to exercise programs by systematic meta-analysis of journals published over 50 years.

Therefore, it is necessary plan to design in advance how and when to provide the opportunity for interaction and social support during interventions. This research was analyzed that configuration of contents and activity based on theoretical steps to increase group interaction and selecting Manitoba during the intervention period so that they could communicate in daily life during the sessions was helped to increase sociality and social relationship.

Friendly-visitor programs have been the focus of conversational interaction, conventional plus games condition attempting to decrease social isolation (Reinke et al., 1981). Subject in both groups improved performance relative to control group and subjects in the conversation plus game condition demonstrated the greatest improvement for memory, self-perceived heath and ratings of sociability were reliable. It is arguing whether applying one certain activity or using various activities or TR promotion techniques for giving multiple stimuli.

Improving self-esteem is one of significant factor to solve old man's isolation. The emergence of depressive symptoms was found to highly related to low self-esteem, negative attitude to ageing, and perceived inactivity (Coleman et al., 1993). Self-esteem and loneliness is related to intergeneration social support on subjective well-being (Tian, 2016).

Even still many argue about the radical effect of TR or specific program for depression, isolation and sociality of older people. However, it is clear that stimulation through diverse activities centered on partner or group and social support-oriented intervention programs can positively influence social development of the elderly. Since Korean society is rapidly aging, further research focusing on the isolation and social problems need to reveal the most appropriate methods and facilitation ways as psycho-social rehabilitations in the elderly.

\section{CONFLICT OF INTEREST}

No potential conflict of interest relevant to this article was reported.

\section{ACKNOWLEDGMENTS}

This research was supported by the Cheongam College research grants in 2017.

\section{REFERENCES}

Buettner L, Voelkl JE. Special issue on positive aging through activity and therapeutic recreation. Ther Recreat J 2006;40:16-57.

Burton E, Farrier K, Hill KD, Codde J, Airey P, Hill AM. Effectiveness of peers in delivering programs or motivating older people to increase their participation in physical activity: systematic review and metaanalysis. J Sports Sci 2018;36:666-678.

Cattan M, White M. Developing evidence based health promotion for older people: a systematic review and survey of health promotion interventions targeting social isolation and loneliness among older people. Int J Health Promot 1998;13:1-9.

Cattan M, White M, Bond J, Learmouth A. Preventing social isolation and loneliness among older adults: a systematic review of health promotion interventions. Aging Soc 2005;25:41-67.

Choi AN, Lee MS, Lim HJ. Effects of group music intervention on depression, anxiety, and relationships in psychiatric patients: a pilot study. J Altern Complement Med 2008;14:567-570.

Chung SD. Predictors of self-esteem among older adults in nursing home. Korean J Gerontol 2004;24:107-122.

Cohen-Mansfield J. The impact of group activities and their content on persons with dementia attending them. Alzheimers Res Ther 2018;10:37.

Cohen-Mansfield J, Perach R. Interventions for alleviating loneliness among older persons: a critical review. Am J Health Promot 2015;29: 
e109-125.

Coleman P, Aubin A, Robinson M, Ivani-Chalian C, Briggs R. Predictors of depressive symptoms and low self-esteem in a follow-up study of elderly people over 10 years. Inter J Geriatr Psychiatry 1993;8:343-349.

Findlay R. Interventions to reduce social isolation amongst older people: where is the evidence? Aging Soc 2003;23:647-658.

Fitzpatrick TR, Spiro A, Kressin NR, Greene E, Boss, R. Leisure activities, stress, and health among bereaved and non-bereaved elderly men: the normative aging study. Omega 2001;43:217-245.

Fokkema T, Knipscheer K. Escape loneliness by going digital: a quantitative and qualitative evaluation of a Dutch experiment in using ECT to overcome loneliness among older adults. Aging Ment Health 2007;11: 496-504.

Getz DA, Karrow A, Kielbaso JJ. Inner city preferences for trees and urban forestry programs. J Arboric 1982;8:258-263.

Glover TD. All the lonely people: social isolation and the promise and pitfalls of leisure. Leisure Sci 2017;40:25-35.

Hill W, Weinert C, Cudney S. Influence of a computer intervention on the psychological status of chronically ill rural women: preliminary results. Nurs Res 2006;55:34-42.

Kahlbaugh PE, Sperandio A J, Carlson AL, Hauselt J. Effects of playing Wii on well-being in the elderly: physical activity, loneliness, and mood. Act Adapt Aging 2011:35:331-344.

Kim SK. Development of lifestyle assessment inventory for wellness of Korean adults. Korean J Phys Educ 2000;39:963-982.

Lee MS. Does the social activity of the elderly mediate the relationship between Social isolation and suicidal ideation? Mental Health Soc Work 2012;9:231-259.

McAuley E, Blissmer B. Self-efficacy determinants and consequences of physical activity. Exerc Sport Sci Rev 2000;28:85-88.

Mosey AC. The concept and use of developmental groups. Am J Occup Ther 1970;24:272-275.

Nicholson NR. A review of social isolation: an important but underassessed condition in older adults. J Prim Prev 2012;33:137-152.

Poscia A, Stojanovic J, La Milia DI, Duplaga M, Grysztar M, Moscato U, Onder G, Collamati A, Ricciardi W, Magnavita N. Interventions targeting loneliness and social isolation among the older people: an update systematic review. Exp Gerontol 2018;102:133-144.

Reinke BJ, Holmes DS, Denney NW. Influence of a "friendly visitor" program on the cognitive functioning and morale of elderly persons. Am J Community Psychol 1981;9:491-504.

Samarel N, Fawcett J, Tulman L. Effect of support groups with coaching on adaptation to early stage breast cancer. Res Nurs Health 1997;20: 15-26.

Shin JS, Lim MJ. The effect of socialbility recovery and life-satisfaction of leisure activity for seniors. J Exerc Rehabil 2010:6;55-64.

Stewart M, Craig D, MacPherson K, Alexander S. Promoting positive affect and diminishing loneliness of widowed seniors through a support intervention. Public Health Nurs 2001;18:54-63.

Tian Q. Intergeneration social support affects the subjective well-being of the elderly: Mediator roles of self-esteem and loneliness. J Health Psychol 2016;21:1137-1144.

Tsai HH, Tsai YF, Wang HH, Chang YC, Chu HH. Videoconference program enhances social support, loneliness, and depressive status of elderly nursing home residents. Aging Ment Health 2010;14:947-954.

Yang K. Causal conditions for loneliness: a set-theoretic analysis on an adult sample in the UK. Qual Quant 2018;52:685-701. 